\title{
The Wood Index: An Innovative Index for Determining Vine Vigour
}

\section{ISSN: 2637-7659}

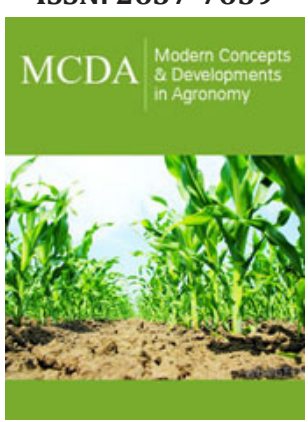

*Corresponding author: Isabella Ghiglieno, Department of Agricultural and Environmental Sciences-Production, Landscape, Agroenergy, University of Milan, Via Celoria 2, 20133, Milan, Italy

Submission: 洞 September 06, 2019

Published: 此 September 23, 2019

Volume 5 - Issue 1

How to cite this article: Isabella Ghiglieno, Paolo Dosso, Bonfiglio Platè, Gianlugi Alario, Leonardo Valenti. The Wood Index: An Innovative Index for Determining Vine Vigour. Mod Concep Dev Agrono.5(2). MCDA.000607.2019. DOI: 10.31031/MCDA.2019.05.000607

Copyright@ Isabella Ghiglieno, This article is distributed under the terms of the Creative Commons Attribution 4.0 International License, which permits unrestricted use and redistribution provided that the original author and source are credited.

\author{
Isabella Ghiglieno ${ }^{1 *}$, Paolo Dosso², Bonfiglio Platè ${ }^{3}$, Gianlugi Alario ${ }^{4}$ and \\ Leonardo Valenti ${ }^{1}$ \\ ${ }^{1}$ Department of Agricultural and Environmental Sciences, Italy \\ ${ }^{2}$ Studio di Ingegneria Terradat, Italy \\ ${ }^{3}$ Appleby Italiana srl, Italy \\ ${ }^{4}$ Casella Machine Agricole srl, Italy
}

\begin{abstract}
Precision farming makes it possible to direct management strategies in relation to the actual needs of crops. This farming management technique, also described as Variable Rate Technology (VRT), works by acquiring images that show the shape, size and vigour of various crops. The images can be obtained using different technologies, such as remote sensing and proximal sensing. Precision farming has been already applied in viticulture for chemical fertilisation management, but it has never been applied to organic fertilisation in this farming sector. In the context of the LIFE VITISOM Project, an innovative VRT technology was designed and validated to manage the organic fertilisation of vineyards. This made it necessary to introduce a system for mapping the vigour of woody branches in the absence of vegetation. In viticulture, organic fertilisation is indeed usually carried out in spring or autumn, when all leaf coverage is commonly absent. With this scope, an innovative index for the quantification of vine vigour (WI-Wood Index) was introduced. The WI has been implemented in the context of the existing MECS-VINE sensor to obtain MECSWOOD reading mode. This case study aims to describe the WI, its assessment and validation, during two phases of vigour map acquisition in 2017/2018 and 2018/2019 in five different Italian viticultural contexts, over a total monitored surface area of $260 \mathrm{ha}$. The results obtained from this experience made it possible to confirm the accuracy of the WI in quantifying vine vigour. Data to be collected during the final phase in 2019/2020 will allow us to further confirm these results.
\end{abstract}

Keywords: Viticulture; Vine vigour; Canopy Index; Wood Index; Organic fertilisation

Abbreviations: NDVI: Normalised Difference Vegetation Index; WI: Wood Index; CI: Canopy Index; BER: Guido Berlucchi; CSV: Cantina Castelvecchi; BDM: Bosco del Merlo; CDA: Conti Degli Azzoni; CBON: Castello Bonomi Tenute in Franciacorta

\section{Introduction}

Precision farming is a farming management technique already known in the agricultural sector [1,2]. It makes possible to perform agronomic intervention taking into account actual cultivation needs. This is possible by calibrating input on the basis of images that show the shape, size and vigour of various crops. The remote sensing technique allows to obtain these images using different technology, such as multispectral images acquired from satellites and airborne or unmanned aerial vehicles (UAV) [3-10]. Proximal sensing represents another instrument for obtaining this kind of information, but in this case the technology is based on various types of sensors suitable for continuous measurements of soil or canopy parameters [11-14]. Viticulture is one of the most extensively investigated sectors, due to its economic significance at European level. The possibility of collecting information about vineyard vegetation development allows farmers to better direct management strategies and calibrate decision-making in relation to the different vigour of the vines in the vineyard. This represents the VRT (Variable Rate Technology) concept as a way of calibrating input according to actual vine requirements [15-17].

Different experiences have been gained in relation to chemical fertilisation management [18] and plant protection $[19,20]$. However, no experience has been gained about the organic fertilisation of vineyards, intended as the application of fertilisers such as compost, manure and solid fraction of digestate. With this scope, in the context of the LIFE15 ENV/IT/000392 LIFE VITISOM Project, an innovative system for VRT organic matter viticulture management in real time was designed and validated. Organic fertilisation in the vineyard is usually carried 
out during autumn or spring, when vegetation is absent or not fully developed. This made it essential in order to work "in real time" (e.g. distributing the organic fertiliser at the same time as assessing vine vigour), to develop a system for evaluating vigour no longer based on the leaf surface but on woody branches without vegetation. This paper describes the process of developing the WI (Wood Index), starting from the existing CI index [20]. In the context of the VITISOM project, the WI was implemented as a new component of the MECS-VINE ${ }^{\circledR}$ sensor already presented by Gatti et al. [20], generating the MECS-WOOD working mode. The validation process was carried out during two phases of data collection (2017/2018 and 2018/2019) in different Italian viticultural contexts over a total of 260 hectares, monitored during each phase.

\section{Case Presentation}

The WI (Wood Index) is represented by a dimensionless number expressed in the same range $(0-1,000)$ as the $\mathrm{CI}$ index (Canopy index). The $\mathrm{CI}$ is a dimensionless data variable between 0 and 1,000 , which essentially represents the vegetation per surface area of the vegetated wall related to each unit of terrainl and can be directly related to variables such as the LAI (Leaf through the WI.
Area Index) and TRV (Tree Row Volume) [20]. The WI is very similar to $\mathrm{CI}$, although it has a narrower range of variability and is centered on lower values, while from a conceptual point of view, it is closely connected with the weight of dry pruning wood that can be measured directly in the vineyard. The WI makes it possible to work only when all leaf coverage is absent, and therefore the identification and quantification of vigour is based on woody branches in the absence of vegetation, net of any other disturbing elements (for example support poles). The activities to implement the WI in MECS-WOOD were organised into two main phases: a first phase taking place during autumn 2016 and the early part of 2017 , with the aim of carrying out validation in autumn/winter $2017 / 2018$, and a second phase based on the results obtained from the first, to be validated in autumn/winter 2018/2019. During each phase, maps were produced using methods based on multispectral satellite data (well known based on the NDVI index), in MECS-VINE reading mode and in MECS-WOOD reading mode. The GANTT chart of the performed activities is represented in Table 1. Feedback collected from technicians in the four testing companies involved in the project (BER, CBON, CDA and CSV) was organised with the aim of measuring and quantifying the precision of the maps obtained

Table 1: GANTT chart of activities carried out in the 2016-2019 period.

\begin{tabular}{|c|c|c|c|c|c|c|c|c|c|c|c|c|c|c|c|c|}
\hline & \multicolumn{4}{|c|}{2016} & \multicolumn{4}{|c|}{2017} & \multicolumn{4}{|c|}{2018} & \multicolumn{4}{|c|}{2019} \\
\hline Trimester & I & II & III & IV & I & II & III & IV & I & II & III & IV & I & Il & III & IV \\
\hline NDVI & & & $\mathrm{x}$ & & & & $\mathrm{x}$ & & & & $\mathrm{x}$ & & & & $\mathrm{x}$ & \\
\hline $\mathrm{CI}$ & & & & & & $\mathrm{x}$ & $\mathrm{x}$ & & & $\mathrm{x}$ & $\mathrm{x}$ & & & $\mathrm{x}$ & $\mathrm{x}$ & \\
\hline WI & & & & & & & & $\mathrm{x}$ & $\mathrm{x}$ & & & $\mathrm{x}$ & $x$ & & & $\mathrm{x}$ \\
\hline
\end{tabular}

Table abbreviations: NDVI indicates maps produced using multispectral satellite data, CI maps produced in MECSVINE reading mode and WI maps produced in MECSWOOD reading mode.

The fifth company (BDM) was involved in map acquisition but not in map evaluation. This investigation provided an evaluation of the correspondence of the different maps with the technicians' personal knowledge of the variability present in the vineyards of the respective reference company. Consequently, technical feedback on each of the maps produced was requested on a scale of 1 to 6 , where 1 was the lowest value of correspondence and 6 the maximum. The effectiveness of the WI in quantifying vine vigour from annual wood without leaf coverage was also supported by comparison between the maps produced with the WI index and those produced with the NDVI and CI indexes. The quantity of data managed in the project is shown in Table 2 and 3, and it is expected that this will grow by a further $25 \%$ by the end of the VITISOM project.

Table 2: Location and main characteristics of the viticultural environments investigated.

\begin{tabular}{|c|c|c|}
\hline $\begin{array}{c}\text { Name of the Wine } \\
\text { Company }\end{array}$ & Location & Main Characteristics \\
\hline BDM & $\begin{array}{c}\text { Annone Veneto and Lison } \\
\text { (Venice and Treviso), Veneto } \\
\text { Region }\end{array}$ & Plain vineyards extending over a large area \\
\hline CSV & $\begin{array}{c}\text { Radda in Chianti (Siena), } \\
\text { Tuscany Region }\end{array}$ & Vineyards characterised by variable slope conditions \\
\hline CBON & $\begin{array}{c}\text { Coccaglio (Brescia), Lombar- } \\
\text { dy Region }\end{array}$ & Plain vineyards and terraces \\
\hline CDA & $\begin{array}{c}\text { Montefano (Ancona), Marche } \\
\text { Region }\end{array}$ & Plain and sloping vineyards characterised by variable counterslope conditions \\
\hline BER & $\begin{array}{c}\text { Corte Franca (Brescia), Lom- } \\
\text { bardy Region }\end{array}$ & Plain vineyards with a high planting density (10000 vines/ha) \\
\hline
\end{tabular}


Table 3: Summary of the surface areas and number of maps produced during surveys at the various production sites.

\begin{tabular}{|c|c|c|c|c|c|c|c|c|}
\hline $\begin{array}{c}\text { Wine Com- } \\
\text { pany }\end{array}$ & $\begin{array}{c}\text { Monitored } \\
\text { Surface Area } \\
\text { (ha) }\end{array}$ & $\begin{array}{c}\text { Number of Par- } \\
\text { cels Monitored }\end{array}$ & $\begin{array}{c}\text { Average Surface } \\
\text { Area of Each Parcel } \\
\text { (ha) }\end{array}$ & $\begin{array}{c}\text { Number } \\
\text { of NDVI } \\
\text { Maps }\end{array}$ & $\begin{array}{c}\text { Number of } \\
\text { CI Maps }\end{array}$ & $\begin{array}{c}\text { Number of } \\
\text { WI Maps }\end{array}$ & $\begin{array}{c}\text { Total Number of } \\
\text { Maps }\end{array}$ & $\begin{array}{c}\text { Total Mapped } \\
\text { Surface Area }\end{array}$ \\
\hline BER & 80 & 36 & 2,22 & 108 & 131 & 65 & 304 & 676 \\
\hline CBON & 20 & 21 & 0,95 & 63 & 125 & 32 & 220 & 210 \\
\hline CDA & 60 & 20 & 3,00 & 60 & 105 & 17 & 182 & 546 \\
\hline BDM & 80 & 43 & 1,86 & 129 & 47 & 10 & 186 & 346 \\
\hline CSV & 20 & 12 & 1,67 & 36 & 49 & 10 & 95 & 158 \\
\hline Total & 260 & 132 & 1,94 & 396 & 457 & 134 & 987 & 1935 \\
\hline
\end{tabular}

\section{Results and Discussion}

\section{WI description}

The process of interpreting vine vigour based on woody branches has involved a substantial modification of the internal MECS-VINE sensor operation algorithms. Effective, original and synergistic use of various computer displays and image processing algorithms was indeed developed: the canopy wall was imaged three times per second during progression along the line, and each individual image was classified in real time using specifically developed image processing algorithms. One of the main problems in interpreting vigour in the absence of vine vegetation is indeed related to the large number of misleading elements, that must be correctly identified and whose influence must be removed from canopy estimation. Light or shade conditions, the presence of poles and weather conditions can affect the accuracy of image interpretation (Figure 1).

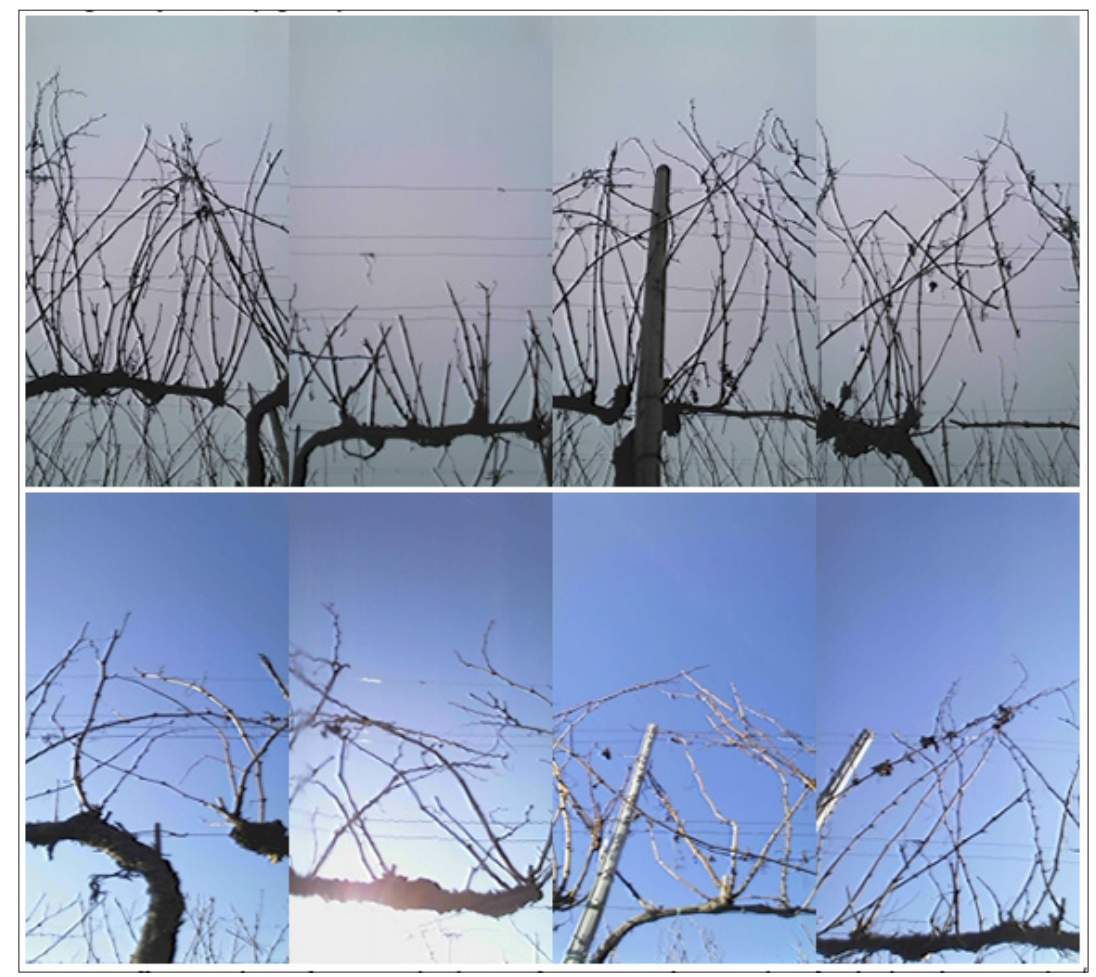

Figure 1: Different condition of canopy in the absence of vegetation. A large number of misleading elements Light or shade conditions, the presence of poles and weather conditions can be present.

With this specific scope, the algorithms were designed with the aim of distinguishing the actual quantity of canopy from the background and other irrelevant targets. This way, real-time image processing of each sample point leads to a canopy quantification that effectively estimates the extent of the wooden part of the canopy (the only part of the canopy that is still in place during autumn/ winter surveys) for each individual sampling location. Each canopy quantification was georeferenced, so that a georeferenced thematic map spatialising the canopy index readings included in the survey could be calculated; in this case, the CI (Canopy Index) took the name of WI (Wood Index), to highlight the fact that only the wooden fraction of the canopy was quantified. The specific operational mode was then called MECS-WOOD, instead of MECS-VINE. 


\section{WI validation process}

At the end of the first phase of monitoring in 2017/2018, comparison between the NDVI maps, CI maps and WI maps showed some discrepancy in relation to some of the WI maps. These results were the consequence of an underperforming behaviour of the algorithm when a combination of the effects of specific lighting conditions and the presence of poles was noticeable. To solve this problem, a large set of statical observations was included. An artificial vine wall (without vegetation), made of real vine shoots collected in the vineyards, has been then built to allow an extensive statical MECS-WOOD sensor verification and calibration. These surveys were carried out during a two-month period in different lighting conditions, and together with the analysis of the early maps created during the second survey in 2018/2019, made it possible to make further modifications to the internal algorithms constituting the WOOD implementation.

Tests obtained from the second phase of validation in 2018/2019 highlighted the important and substantial benefits due to the improvements made to the algorithm. Figure 2 shows an example of comparison between a 2017 and 2018 WI map. Results obtained from technicians' evaluations in conclusion of the second phase of monitoring (2018/2019) showed that the values recorded for the WI index were equal to or higher than those recorded for the CI and NDVI indices, highlighted in Figure 3 and 4. As mentioned previously, we are still collecting data from the 2019/2020 survey. The results obtained from this last survey may confirm the correct functioning of MECS-WOOD mode.

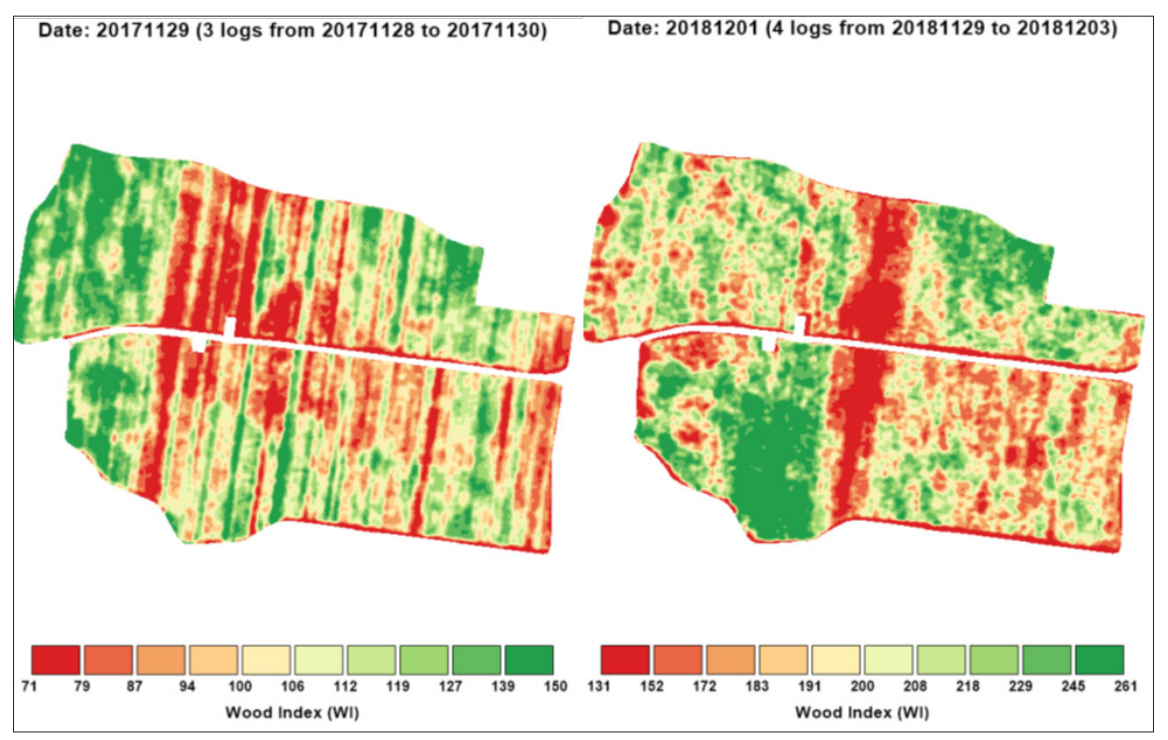

Figure 2: Example of a WI map produced during the first phase of validation in $2017 / 2018$ (on the left) and a WI map produced during the second phase in 2018/2019. The colour of the maps shows the different level of vigour: red indicates low vigour, yellow medium vigour and green a high level of vigour.

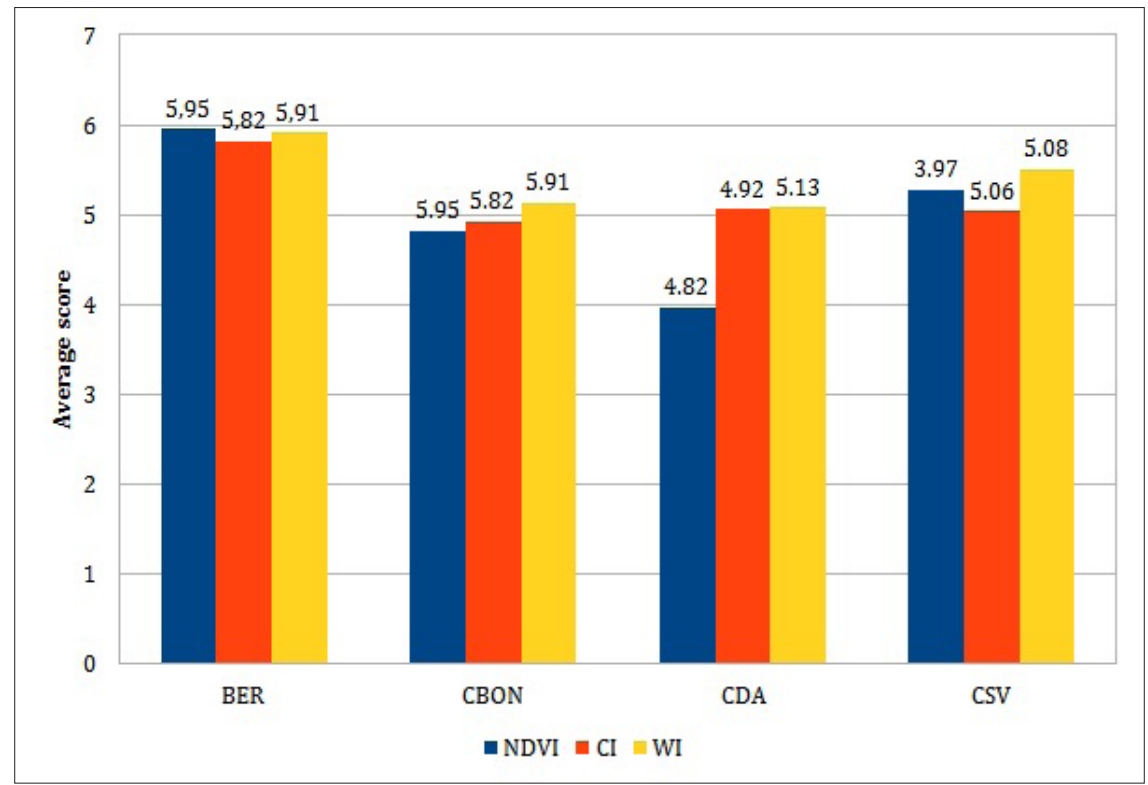

Figure 3: Results obtained from technicians' evaluation after the 2018/2019 survey, to compare the WI with the NDVI and CI. The results are divided by wine company. 


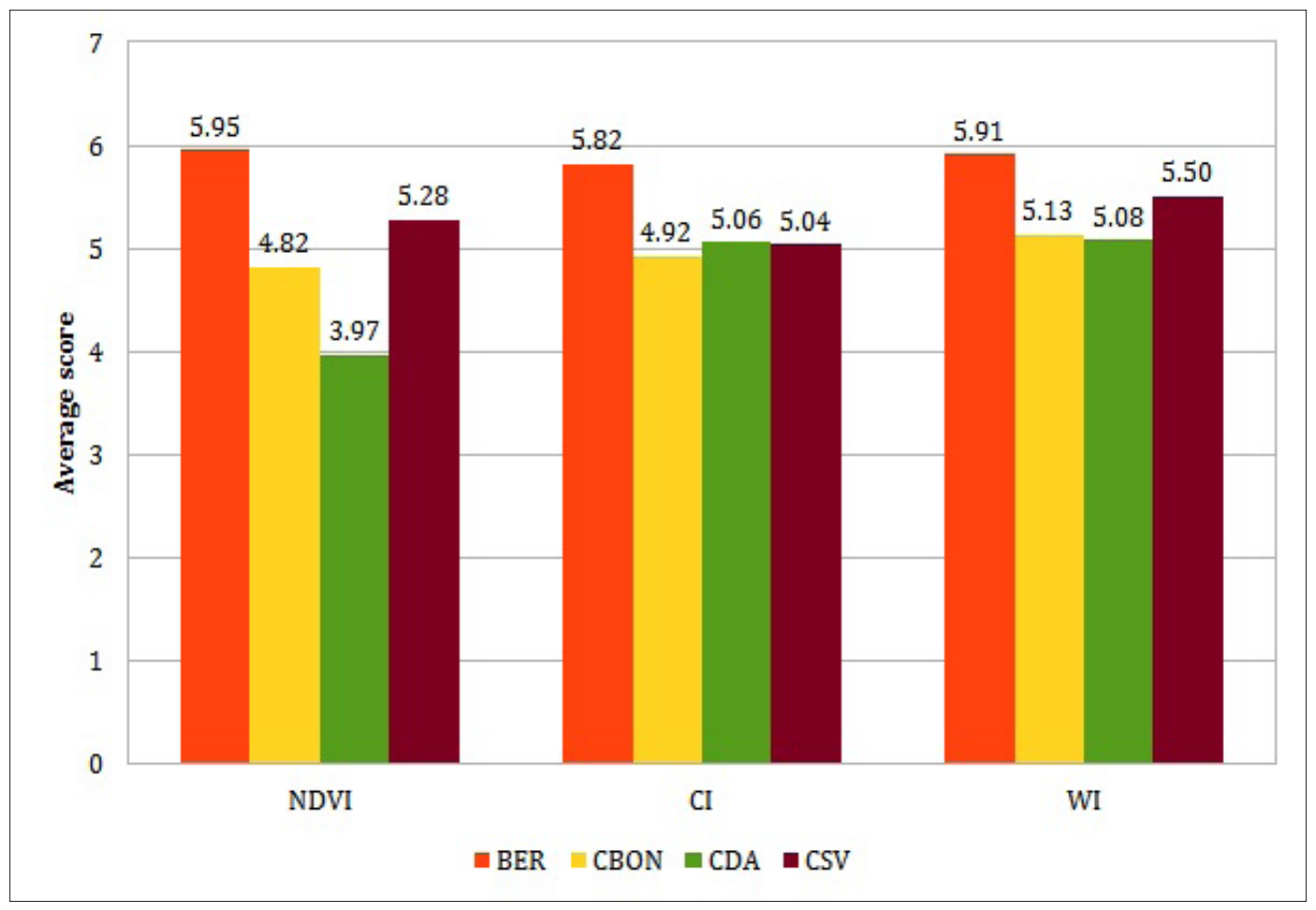

Figure 4: Results obtained from technicians' evaluation after the 2018/2019 survey, to compare the WI with the NDVI and CI. The results are divided by the type of index used.

\section{Acknowledgment}

The authors thank all the project partners for their cooperation, and specifically Casella Macchine Agricole, the University of Padua (Prof. Pitacco's research group), Consorzio Italbiotech, West Systems, Castello Bonomi Tenute in Franciacorta, Conti degli Azzoni, Guido Berlucchi and the research groups of Prof. Adani, Prof. Pessina and Dott. Corsi.

\section{Conflict of Interest}

The authors declare that Studio di Ingegneria Terradat and Appleby Italiana, together with Casella Macchine Agricole, are part of the TEAM Group, which deals with the production and marketing of the MECS-VINE sensor and its implementation as MECS-WOOD.

\section{References}

1. Auernhammer $H$ (2001) Precision farming-the environmental challenge. Computers and Electronics in Agriculture 30(1-3): 31-43.

2. Blackmore S (1994) Precision Farming: An Introduction. Outlook on Agriculture 23(4): 275-280.

3. Atzberger C (2013) Advances in remote sensing of agriculture: Context description, existing operational monitoring systems and major information needs. Remote Sensing 5(2): 949-981.

4. Mulla DJ (2013) Twenty five years of remote sensing in precision agriculture: Key advances and remaining knowledge gaps. Biosystems Engineering 114(4): 358-371.

5. Salamí E, Barrado C, Pastor E (2014) UAV flight experiments applied to the remote sensing of vegetated areas. Remote Sensing 6(11): 1105111081.
6. Primicerio J, Di Gennaro SF, Fiorillo E, Genesio L, Lugato E, et al. (2012) A flexible unmanned aerial vehicle for precision agriculture. Precision Agriculture 13(4): 517-523.

7. Zhang C, Kovacs JM (2012) The application of small unmanned aerial systems for precision agriculture: A review. Precision Agriculture 13(6): 693-712.

8. Matese A, Capraro F, Primicerio J, Gualato G, Di Gennaro SF, et al. (2013) Mapping of vine vigor by UAV and anthocyanin content by a non-destructive fluorescence technique. $9^{\text {th }}$ European Conference on Precision Agriculture (ECPA), Lleida, Spain.

9. Hall A, Lamb DW, Holzapfel B, Louis J (2002) Optical remote sensing applications in viticulture-A review. Australian Journal of Grape and Wine Research 8(1): 36-47.

10. Viscarra Rossel RA, Adamchuk VI, Sudduth KA, McKenzie NJ, Lobsey C (2011) Chapter Five-Proximal soil sensing: An effective approach for soil measurements in space and time. Advances in Agronomy 113: 243-291.

11. Anastasiou E, Balafoutis A, Darra N, Psiroukis V, Biniari A, et al. (2018) Satellite and proximal sensing to estimate the yield and quality of table grapes. Agriculture 8(7): 94.

12. De Benedetto D, Castrignano A, Diacono M, Rinaldi M, Ruggieri S, et al. (2013) Field partition by proximal and remote sensing data fusion. Biosystems Engineering 114(4): 372-383.

13. Di Gennaro SF, Matesea A, Giolia B, Toscanoa P, Zaldeia A, et al. (2017) Multi sensor approach to assess vineyard thermal dynamics combining high resolution unmanned aerial vehicle (UAV) remote sensing and wireless sensor network (WSN) proximal sensing. Scientia Horticulturae 221: 83-87.

14. Lawes RA, Robertson MJ (2011) Whole farm implications on the application of variable rate technology to every cropped field. Field Crops Research 124(2): 142-148.

15. Bullock DS, Ruffo ML, Bullock DG, Bollero GA (2009) The value of variable rate technology: An information-theoretic approach. American Journal of Agricultural Economics 91(1): 209-223. 
16. Bramley RGV, Trought MCT, Praat JP (2011) Vineyard variability in Marlborough, New Zealand: characterising variation in vineyard performance and options for the implementation of Precision Viticulture. Australian Journal of Grape and Wine Research 17(1): 72-78.

17. Gatti M, Squeri C, Garavani A, Frioni T, Dosso P, et al. (2019) Effects of Variable Rate Nitrogen Application on cv. Barbera Performance: Yield and Grape Composition. American Journal of Enology and Viticulture 70(2): 188-200.

18. Llorens J, Gil E, Llop J, Escola A (2010) Variable rate dosing in precision viticulture: Use of electronic devices to improve application efficiency. Crop Protection 29(3): 239-248.
19. Gil E, Escola A, Rosell JR, Planas S, Vald L (2007) Variable rate application of plant protection products in vineyard using ultrasonic sensors. Crop Protection 26(8): 1287-1297.

20. Gatti M, Dosso P, Maurino M, Merli MC, Barbizon F, et al. (2016) MECSVINE®: A new proximal sensor for segmented mapping of vigor and yield parameters on Vineyard Rows. Sensors (Basel) 16(12).

For possible submissions Click below: 